\title{
Law enforcement officers' opinions about gun locks: anchors on life jackets?
}

\author{
T Coyne-Beasley, R M Johnson
}

\begin{abstract}
Objectives-One way law enforcement officers support firearm safety is by promoting the use of gun locks. This investigation examined law enforcement officers' willingness to use gun locks on their own guns, as well as their opinions regarding gun locks in general.

Setting-Law enforcement officers from an urban agency in the southern region of the United States.

Methods-Free keyed cable gun locks were distributed to all law enforcement officers in one agency who wanted one, and then an anonymous questionnaire survey was conducted about their subsequent use of, and attitudes toward, these devices. Results-About half of the 207 officers collected gun locks $(n=103)$. Nearly three quarters $(73 \%)$ completed and returned the questionnaire. Two thirds reported that they were not using the gun lock they collected $(65 \%)$, and over half disagreed that gun lock use should be required $(56 \%)$. Very few cited any actual or potential technical problems with the device. An important reason given for non-use of gun locks related to being able to access the weapon quickly in case of an emergency. Conclusions-The findings highlight the need for further investigation into law enforcement officers' attitudes toward gun locks, the degree to which their attitudes affect their firearm safety counseling, and the need to develop a gun safety device that can be disengaged quickly.
\end{abstract}

Injury Prevention Research Center and Department of Pediatrics, Division of Community Pediatrics, Campus Box 7225, Wing C, School of Medicine, University of North Carolina at Chapel Hill, Chapel Hill, NC 27599-7225, USA

$\mathrm{T}$ Coyne-Beasley

Department of Health Behavior and Health Education, University of North Carolina at Chapel Hill, School of Public Health

R M Johnson

Correspondence to: Dr Coyne-Beasley coybea@med.unc.edu

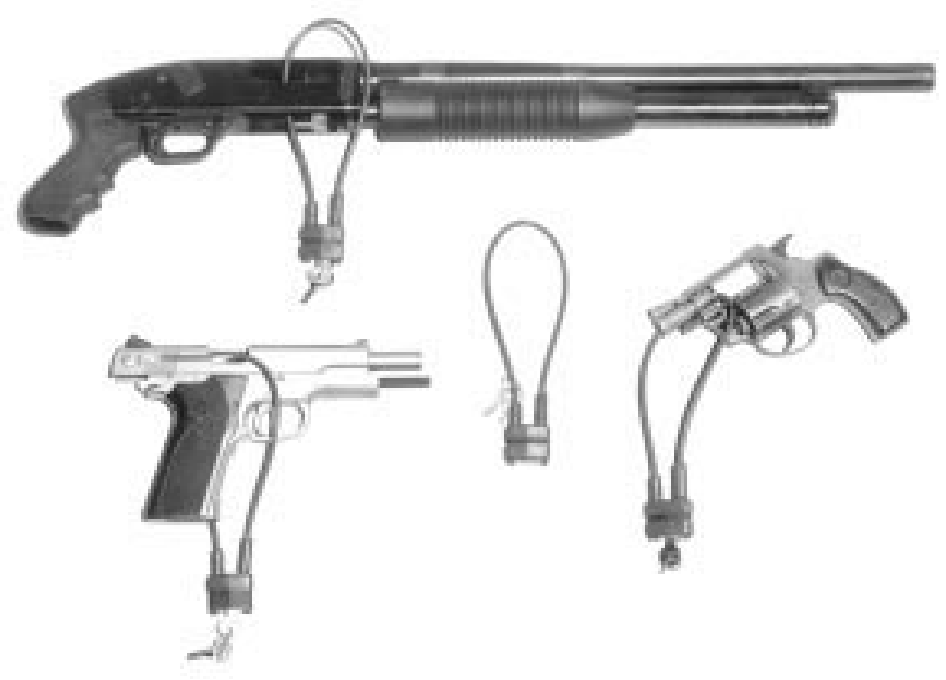

Figure 1 Various firearms showing keyed cable gun locks (thanks to Ed Shenkman Photography, Chapel Hill, North Carolina).
(Injury Prevention 2001;7:200-204)

Keywords: firearms/guns; law enforcement officers; gun locks

Suicide, homicide, and unintentional injury deaths due to firearms represent a major public health problem in the United States. ${ }^{1-3}$ Young people are over-represented among such deaths. ${ }^{23}$ The total firearm related injury death rate for youth in the United States is 16 times higher than the rate for other industrialized nations, and the unintentional firearm related injury death rate is nine times higher. ${ }^{45}$

It has been suggested that young people's relatively easy access to firearms is a major contributor to this epidemic. ${ }^{6-11}$ An estimated $35 \%$ to $50 \%$ of homes in the United States have firearms. ${ }^{12-14}$ Adults, and parents in particular, often store guns in a manner in which they are readily accessible to youth; this includes keeping guns loaded and not locked up, and storing extra ammunition along with the firearm. ${ }^{12}{ }^{15-17}$ In a recent analysis of nationally representative data, among parents who had firearms in their home, nearly half had at least one firearm that was not locked up. ${ }^{18}$

Gun locks are advocated as a strategy to prevent unauthorized access of weapons. ${ }^{816} 19$ Keyed cable gun locks render guns inoperable because the gun must be unloaded to install the device, and a steel cable runs through the barrel for a revolver, or through the ejection port for semiautomatics, rifles, and shotguns. A keyed lock secures the cable (fig 1).

Law enforcement officers are at the forefront of health promotion about the importance of using gun locks. Gun lock giveaway programs have been conducted by law enforcement agencies in several states, including New Jersey, North Carolina, Illinois, Florida, and Washington, DC. ${ }^{20}$ Project HomeSafe is a national program that works with law enforcement agencies to conduct firearm safety education and gun lock distribution at the local level; the project has conducted distribution programs in over 100 agencies in 40 states. $^{21}$

Some law enforcement agencies have begun promoting gun locks to their officers as well as to community citizens. In 1998 Boston became the first municipality to mandate that citizens secure guns by using a locked container, a tamper resistant mechanical lock, or another safety device. In compliance with the mandate, the Boston Police Department trained and supplied all sworn officers with Saf-T-Lok gun locks. Since Boston's initiative, law enforcement agencies in three additional states have begun using the Saf-T-Lok, and scores of other agencies are considering the idea. $^{22}$ Even 
Gun lock questionnaire

1. Are you using the gun locks?

$$
\square \text { Yes } \quad \square \text { No }
$$

2. Do you think that all gun owners should be required to use these locks?

$$
\square \text { Yes } \quad \square \text { No }
$$

2a. If no, why not?

3. Have you had difficulty using the gun locks? (eg, broken lock etc)

$$
\square \text { Yes } \quad \square \text { No }
$$

If yes, please describe.

4. What types of problems do you think could occur with these locks?

5. Do you have children (under the age of 18 years)?

$\square$ Yes $\quad \square$ No

5a. If $\underline{\text { yes, }}$ what are their ages?

6. Demographic information:

Gender
Age
Race

7. Rank (eg, Corporal)

(You may use the reverse side for additional comments)

Figure 2 Questionnaire.

though law enforcement officers educate citizens about gun locks, and are encouraged to use them in their own homes, little is known about officers' personal use of these devices. A recent study suggests that officers do not practice safe firearm storage generally, and, in particular, do not use safety locks. ${ }^{23}$ The purpose of the present investigation was to determine officers' use of and opinions regarding keyed cable gun locks. We distributed gun locks to law enforcement officers, along with a questionnaire inquiring about their attitudes and behavior concerning gun lock use.

\section{Methods}

In November and December of 1998, a ranking officer distributed gun locks-free of charge - to law enforcement officers in a local agency in the southern region of the United States. (The ranking officer was carrying out the gun lock distribution on both a volunteer and an official basis.) All officers with service weapons were invited to obtain a keyed cable gun lock (fig 1). At the time officers collected gun locks, they were given an anonymous self report questionnaire (fig 2), which was to be completed and returned after they had the opportunity to use and evaluate the lock. The questionnaire was short to encourage completion and be respectful of officers' time. It was a self report survey with 12 items. There were four yes/no questions about personal and required use of gun locks, difficulty with gun lock use, and whether the officer had children less than 18 years old. There were eight open ended questions that included demographic information. Attached to the questionnaire was a cover letter explaining the study, the letter was signed by a ranking officer and by the principal investigator. Before the gun lock distribution, the agency had been involved in a number of firearm injury prevention activities, including a firearm safety education and gun lock distribution program in which officers distributed the same locks they were being offered to citizens in their jurisdiction. These activities were sponsored jointly by the law enforcement agency and the first author's Injury Prevention Project.

For the convenience of the officers, collection boxes for the questionnaire were placed in various substations throughout the jurisdiction of the agency. Reminder notices were sent to the officers twice. We stopped collecting surveys in February 1999. Participation was voluntary and not a prerequisite for receiving a gun lock. The Institutional Review Board at the University of North Carolina School of Medicine approved this study.

\section{Results}

Of the 207 officers in the agency who had service weapons, 103 collected gun locks and were given questionnaires and 75 were returned (73\%). Most respondents were male (90\%), half were African American (50\%), and the mean age was 33 years. Most respondents were non-ranking officers $(73 \%)$, and less than one half $(43 \%)$ had children younger than 18 years old. The demographic characteristics of the officers who collected gun locks and completed the questionnaire were similar to the demographic characteristics for the officers in the agency, which were male $(89 \%)$, African American (42\%), and non-ranking officers $(83 \%)$. Agency information was not readily available for officers' ages and presence of children younger than 18 years old.

The majority $(65 \%)$ reported that they were not using the gun lock that was distributed to them. In an open ended question probing about reasons for not using the lock, two officers wrote that although they were not using a gun lock, they were using a different extrinsic safety device, such as a lock box or gun safe. Of those who reported using the gun lock, just one reported having any difficulty with it. He had difficulty opening the lock quickly. Both African Americans $\left(\chi_{1}^{2}=11.7, \mathrm{p}<0.001\right)$ and those with children $\left(\chi_{1}^{2}=11.3, \mathrm{p}<0.001\right)$ were more likely to use the gun lock compared with white officers and those without children, respectively. Interestingly, the two findings are confounded; white officers in this study were significantly less likely to have children compared with African Americans $\left(\chi_{1}^{2}=3.89\right.$; $\mathrm{p}<0.05)$. There was no evidence of different patterns of gun lock use by other characteristics (table 1). 
Table 1 Selected characteristics and gun lock usage by law enforcement officers' in a southern city, $1998(n=72)^{\star}$

\begin{tabular}{|c|c|c|c|c|}
\hline Characteristic & $\begin{array}{l}\text { No (\%) using gun } \\
\text { lock }\end{array}$ & $\begin{array}{l}\text { No (\%) not using } \\
\text { gun lock }\end{array}$ & $\chi_{d f}^{2}$ & $p$ Value \\
\hline \multicolumn{5}{|c|}{ Should all gun owners should be required to use gun locks? } \\
\hline Yes & $21(84)$ & $10(23)$ & $24.27_{1}$ & $<0.001$ \\
\hline \multicolumn{5}{|c|}{ Have you had difficulty using the lock? } \\
\hline Yes & $1(4)$ & $1(2)$ & $0.18_{1}$ & 0.669 \\
\hline \multicolumn{5}{|c|}{ Do you have children younger than 18 years of age? } \\
\hline Yes & $17(68)$ & $12(27)$ & $11.32_{1}$ & $<0.001$ \\
\hline \multicolumn{5}{|l|}{ Gender } \\
\hline Male & $22(88)$ & $38(90)$ & $0.10_{1}$ & 0.749 \\
\hline \multicolumn{5}{|l|}{ Race } \\
\hline Black & $19(76)$ & $14(33)$ & $11.72_{1} \dagger$ & $<0.001$ \\
\hline White & $5(20)$ & $26(62)$ & & \\
\hline \multirow[t]{2}{*}{ Hispanic } & $1(4)$ & $2(5)$ & & \\
\hline & Mean $(S D)$ & Mean $(S D)$ & $F$ & \\
\hline Age & $\begin{array}{l}32.05(8.39) \\
(n=23)\end{array}$ & $\begin{array}{l}33.78(7.30) \\
(\mathrm{n}=42)\end{array}$ & 1.03 & 0.31 \\
\hline
\end{tabular}

*Three respondents did not answer the gun lock use question. Not all the cross tabulated frequency tables sum to 72 due to missing data. Missing data are not factored in $\chi^{2}$ statistics or percentage estimates.

†For race-ethnicity, the significance test compared whites to blacks, omitting Hispanics.

Fewer than half of the officers (44\%) agreed that gun owners should be required to use gun locks. Not surprisingly, those using the gun lock were more likely to support the requirement than those not using it; about $84 \%$ of the respondents who reported that they were using the gun lock were in favor of such a requirement. In an open ended probe follow up question, officers provided explanations why they disagreed with the mandated use of gun locks. Their reasons included: the belief that it is not practical for everyone to use them; an inability to access the gun quickly enough in an emergency; disapproval of government regulation of firearm ownership and storage; challenges in enforcing such a mandate; and the belief that it is possible to keep guns out of the reach of children without using a gun lock.

Officers who were not using the device expressed concern about the fact that using one makes it harder to operate the gun in the event of a break-in. One wrote: "In an emergency you may have problems taking the lock off, for example if a break-in is in progress, you are under stress and may not be able to find the key or open the lock quickly". Another wrote: "a potential problem with the lock is that if someone breaks into your house while you're sleeping, you may be too sleepy to get the lock off effectively", and "using a gun lock is like putting an anchor on a life jacket".

Although most officers did not identify any possible technical problems with the lock, a few raised concerns related to the key and key mechanism. Several were worried about the possibility of losing the key. Another officer felt the key mechanism could rust from moisture and subsequently become difficult to open.

\section{Discussion}

When we offered free gun locks to officers with service weapons, about half chose to obtain them. Although subjects within the sample were highly motivated, having voluntarily picked up a lock, only one third indicated that they were actually using it. The results suggest that officers with children were more likely to use the device, but it is not clear whether this finding is a consequence of the facts that white officers were significantly less likely to both have children and use the gun lock, compared with African American officers. Officers had few concerns about the safety of gun locks but some were worried that guns secured with the locks might not be accessible when needed for self protection.

This small scale investigation had limitations. First, because of the self report nature of the questionnaire, respondents were free to skip questions and this resulted in a small amount of missing data. Additionally, the small sample size posed a challenge to testing for statistical significance of some associations. This was a convenience sample of officers within one law enforcement agency in the southern United States who chose to pick up a gun lock. Therefore, the findings cannot be generalized to either the agency itself, or to law enforcement officers in other locations. This study also can not generalize to officers' attitudes toward all locking or storage devices. Despite these limitations, the findings are thought provoking and highlight the need for further research about law enforcement officers' attitudes and opinions on gun locks.

This study showed that officers' patterns of gun lock use do not agree with what they promote to the public. These findings are consistent with a previous study showing that the most common recommendations about gun safety given by officers to inquiring citizens included trigger locks, but that only a small proportion of the officers recommending triggers locks used the devices themselves. ${ }^{23}$ What the two studies may be revealing is that officers' firearm related attitudes and practices are discrepant from what they recommend to citizens. Our field experience suggests that the reason for this discrepancy relates to the fact that officers feel vulnerable to attack or home break-ins, and thus feel the need to protect themselves with firearms. Officers may believe they are at an increased risk of being victimized, which makes them even less likely to use gun locks. Whether law enforcement officers actually have an increased risk for assault while off duty has not yet been established.

Officers' incongruity raises several points to consider for research and injury control practice. First, it needs to be clarified whether they feel that everyone except for the officers should employ safe storage practices, or whether they feel that safe storage is not a necessary measure in general. Next, it must be determined whether law enforcement officers can effectively promote gun safety devices if they do not personally endorse them. To what extent do personal behaviors affect a professionals' ability to provide health education? Finally, it is important to build links with officers so that they and health professionals can learn from one another and, eventually, reduce the number of people being injured by firearms.

Officers' interest in keeping guns accessible for self protection implies that a safety device is needed that can be disengaged quickly. One officer supported this point when he said, "If the gun is for protection it needs to be quickly 
accessible; therefore, the lock should have a push button code lock that can be accessed even in the dark". The Saf-T-Lok, which is used by the Boston Police Department, is superior to the keyed cable gun lock in that it can reportedly be unlocked in seconds by pushing a sequence of buttons, even in the dark. ${ }^{24}$ Unfortunately, it is substantially more expensive: $\$ 80-\$ 120$ as compared to $\$ 10$ for a keyed cable gun lock.

It is also important to mention that most extrinsic gun safety devices, including keyed cable gun locks, have not been rigorously evaluated. ${ }^{8}$ In fact, some devices have even been recalled after going on the market. ${ }^{25} 26$ Most recently, Project HomeSafe discontinued distribution of gun locks after it came to their attention that the locks could be disassembled in response to a large amount of force. ${ }^{25}$ These types of problems may elicit distrust of gun safety technology by law enforcement officers, and may be an underlying reason for the low gun lock use rates in this study. However, our study and gun lock distribution took place before Project HomeSafe.

\section{Implications for prevention}

The general public looks to officers' for gun safety advice, and it is thus important to have officers' support when promoting safety devices. $^{23} 27$ This research demonstrated that many officers do not use safety locks, probably because they believe these devices may hinder their access to their weapon if needed in an emergency. Considering recent events related to safety lock recalls, it is also likely that officers are concerned about the efficacy of devices like keyed cable gun locks. Thus, we support the continued development and evaluation of extrinsic safety devices, personalized guns, and other engineering efforts to ensure that those keeping guns for self protection can simultaneously prevent the unauthorized release of their weapon. ${ }^{8}$

Law enforcement officers and injury prevention professionals should continue to work together to combat firearm injuries utilizing their complimentary strengths and with recognition of their differences. Officers and injury prevention professionals may have different philosophies regarding firearm safety education and interventions. While the injury community often focuses on gun availability in general as a hazard, officers tend to be more conservative and are concerned primarily about guns in the hands of criminals and children - and may actually support the rights of citizens to own guns. In lieu of industry wide improvements to firearms to prevent their unauthorized discharge, officers and injury prevention professionals should discuss firearm safety education components such as which safety and/or storage devices to recommend (devices that officers would feel comfortable using are probably preferable) and alternative strategies to keep families safe.

Law enforcement officers are important partners in preventing firearm related injuries; and we believe they are to be commended for
Key points

- Law enforcement officers are at the forefront of health promotion about gun safety and the use of gun locks.

- Many law enforcement officers in this study $(65 \%)$ were not using the gun locks they promoted to the public.

- The primary reason reported for not using the gun locks was a perceived inability to access firearms quickly in case of an emergency or home invasion.

- Officers' firearm related attitudes and practices are discrepant from what they recommend to citizens.

- This study demonstrates the need for further investigation into law enforcement officers' attitudes about gun locks and other safety devices.

(1) Do officers think that everyone except officers, should use gun locks?

(2) To what extent do officers' personal gun safety practices and use of devices affect the safety counseling and information they provide?

(3) Which safety devices do law enforcement officers feel comfortable using on their own firearms?

- We support the continued development and evaluation of extrinsic safety devices, personalized guns, and other engineering efforts to ensure that those keeping guns for self protection, especially law enforcement officers, can access their firearms quickly and simultaneously prevent the unauthorized release of their firearms.

their prevention efforts. They go beyond their job responsibilities as those who enforce the law by participating in activities such as gun lock distributions and gun exchange programs. Additionally, they are instrumental in suggesting, developing, and evaluating gun safety technologies.

The authors appreciate the participation of the law enforcement agency that made this study possible. The Institutional Review Board at the University of North Carolina at Chapel Hill School of Medicine approved this investigation. Funding was provided by the Robert Wood Johnson Foundation through the Minority Medical Faculty Development Program and by the William T Grant Foundation through the Faculty Scholars Program. The first author is a recipient of both awards.

1 Centers for Disease Control and Prevention. Nonfatal and fatal firearm-related injuries-United States, 1993-1997. fatal firearm-related injuries-United States, 1993-1

MMWR Morb Mortal Wkly Rep 1999;48:1029-34.
2 Centers for Disease Control and Prevention. FirearmCenters for Disease Control and Prevention. Firearm-
related deaths and hospitalizations-Wisconsin, 1994. MMWR Morb Mortal Wkly Rep 1996;45:757-60.

MMWR Morb Mortal Wkly Rep 1996;45:757-60.
3 Centers for Disease Control and Prevention. FirearmCenters for Disease Control and Prevention. Firearm-
related years of potential life lost before age 65-United States, 1980-1991. MMWR Morb Mortal Wkly Rep 1994;43:609-12.

4 Centers for Disease Control and Prevention. Rates of homicide, suicide, and firearm-related deaths among children-26 industrialized countries. MMWR Morb Mortal Wkly Rep 1997;45:101-5.

5 Krug EG, Dahlberg LL, Powell KE. Childhood homicide, suicide, and firearm deaths: an international comparison. World Health Stat Q 1996;49:230-5.

6 Wintemute GJ, Teret SP, Kraus JF, et al. When children shoot children: 88 unintended deaths in California. $\mathcal{F} A M A$ 1987;257:3107-9.

7 Grossman DC, Reay DT, Baker SA. Self-inflicted and unintentional firearm injuries among children and adolescents: the source of the firearm. Arch Pediatr Adolesc Med 1999;153:875-8. 
8 Freed LH, Vernick JS, Hargarten SW. Prevention of firearmrelated injuries and deaths among youth: a product-oriented
approach. Pediatr Clin North Am 1998;45:427-38.

9 Nelson DE, Grant-Worley JA, Powell K, et al. Population estimates of household firearm storage practices and firearm carrying in Oregon. $\mathscr{f} A M A$ 1996;275:1744-8.

10 Martin JR, Sklar DP, McFeeley P. Accidental firearm fatalities among New Mexico children. Ann Emerg Med 1991;20:58-91.

11 Beaver BL, Moore VL, Peclet M, et al. Characteristics of pediatric firearm fatalities. F Pediatr Surg 1990;25:97-100.

2 Senturia YD, Christoffel KK, Donovan M. Children's household exposure to firearms: a pediatric practice-based survey. Pediatrics 1994;93:469-75.

13 Bureau of Justice Statistics, United States Department of Justice. Sourcebook of criminal justice statistics, 1996. Wat. Sourcebook of criminal justice statistics, 1996.

14 Cook PJ, Ludwig J. Guns in America: results of a national survey on firearm ownership and use. Washington, DC: Police vey on firearm ownersh

15 Hemenway D, Solnick SI, Azrael DR. Firearm training and storage. $\mathscr{f} A M A$ 1995;273:46-50.

16 Sinauer N, Annest J, Mercy J. Unintentional, nonfatal Sinauer N, Annest J, Mercy J. Unintentional,
firearm-related injuries. $7 A M A$ 1996;275:1740-3.

17 Weil DS, Hemenway D. Loaded guns in the home: analysis of a national random survey of gun owners. $f A M A$ 1992;267:3033-7.

18 Schuster MA, Franke TM, Bastain AM, et al. Firearm storage patterns in US homes with children. Am F Public Health 2000;90:588-94.
19 Lee R, Harris $M$. Unintentional firearm injuries: the price of protection. Am f Prev Med 1993;9(suppl):16-20.

20 Center to Prevent Handgun Violence, Law Enforcement Relations Department. Child safety lock giveaway programs. Washington DC: Center to Prevent Handgun Violence, 1999.

21 National Sports Shooting Foundation. Project HomeSafe program description. Available online at http:// program description. Available online at htej://

22 Matthews J. Boston to require child-proof locks on its police department handguns. Move is likely to be used as precedent in effort to make guns safer. The Baltimore Sun. 16 December 1998: 3A.

23 Denno DM, Grossman DC, Britt J, et al. Safe storage of handguns. What do police recommend? Arch Pediatr Adolesc Med 1996;150:927-31.

24 Dulcamaro S. Saf-T-Lok. Keynotes. 1997: 35-9.

25 National Sports Shooting Foundation. Statement concerning Project HomeSafe cable locking device. Available online at http://www.projecthomesafe.org. Accessed: 12 October 2000 .

26 United States Consumer Product Safety Commission. CPSC, Master Lock Co announce recall to replace gun locks. Available online at http://www.cpsc.gov/cpscpub/prerel/ prhtm100/00149.htm

27 Webster DW, Wilson MEH, Duggan AK, et al. Parents' beliefs about preventing gun injuries to children. Pediatrics 1992;89:908-14.

\section{Americans favor cars over kids}

America's long love affair with the car, complete with gifts on Valentine's Day, would appear to be going a bit too far, a poll shows. The nationwide online survey by Ohio based Progressive Insurance found that $45 \%$ of married Americans ranked their cars as the thing they considered most important to them. In answer to separate questions regarding their preferences, only $6 \%$ rated their children as important and just $10 \%$ said their spouse or significant other was important to them, the survey said. The survey, conducted January 5-15 and based on answers from 516 respondents, found that $84 \%$ of Americans love their cars while $32 \%$ have actually given their four wheeled gas guzzler a name. Seventeen per cent of male participants planned to buy their vehicle a gift on Valentine's Day, the poll said. It did not say what gifts might be handed out for the occasion but Progressive, the fourth largest auto insurance company in the United States, suggested rose scented air fresheners or a vintage can of motor oil (Reuters, January 2001).

\section{Bullying is everywhere!}

In the first week of February 2001 Australians could not help but confronted with the widespread nature of bullying:

- A highly publicised court case had two former student boarders from an elite private school facing charges for assault and the atmosphere at the school described as having an "entrenched culture" of bullying.

- A member of Federal Parliament publicising an event in which he was "stood over" and threatened by three other members of Parliament.

- After a series of serious incidents and legal cases involving victimisation, intimidation, violent inductions, and sexual harassment the entire armed forces of Australia stood down for two hours to attend meetings and watch a video from the Commanding Officer stating that these practices were entirely unacceptable. 